\title{
Enabling access to new WHO essential medicines: the case for nicotine replacement therapies
}

\author{
Sandeep P Kishore ${ }^{1,5^{*}}$, Asaf Bitton ${ }^{2}$, Alejandro Cravioto ${ }^{3}$, Derek Yach ${ }^{4}$
}

\begin{abstract}
Nicotine replacement therapies (NRT) are powerful tools for the successful treatment of nicotine addiction and tobacco use. The medicines are clinically effective, supported by the Framework Convention on Tobacco Control, and are now World Health Organization-approved essential medicines. Enabling global access to NRT remains a challenge given ongoing confusion and misperceptions about their efficacy, cost-effectiveness, and availability with respect to other tobacco control and public health opportunities. In this commentary, we review existing evidence and guidelines to make the case for global access to NRT highlighting the smoker's right to access treatment to sensibly address nicotine addiction.
\end{abstract}

Tobacco use kills 5.4 million people annually. Even if no children started smoking in the future, 8.3 million people will die annually of tobacco-related diseases by 2030 . Unless tobacco cessation and control vastly improves, the death toll from tobacco this century will easily reach an estimated 1 billion deaths [1]. In this paper, we discuss the benefits and challenges of enabling access to pharmacotherapies [nicotine replacement therapies (NRTs)] to treat nicotine dependence and bolster tobacco cessation in low and middle income countries (LMIC).

In March 2009, NRTs (specifically, nicotine gums and patches) were added to the Model List of Essential Medicines by the World Health Organization (WHO) [2]. Essential medicines are defined as those that satisfy the priority health care needs of the population, and the Essential Medicines List (EML) is used by over 160 governments as a guide for determining which medicines should be made available to their citizens at low cost (http://www.who.int/medicines/en/ and Figure 1). The addition of a medicine to the international EML directly encourages individual nations to add the drug to their national EML and to internal drug registries. This is an important logistical step. Many countries (e.g. South Africa) restrict drug importations to medicines on national EML and registries. Similarly, several

\footnotetext{
* Correspondence: sunny.kishore@gmail.com

'Weill Cornell/Rockefeller/Sloan-Kettering Tri-Institutional MD-PhD Program, New York, New York, USA

Full list of author information is available at the end of the article
}

foundations and major charities base their medicine supply on the WHO EML. Medicines not on the international or national EML are often not available or are simply unaffordable in LMIC.

In this context, we argue that in light of the increasing global burden of tobacco dependence and the clinical utility of NRT, these new WHO essential medicines can and should be available more widely. Let us be clear at the outset. We do not argue that every smoker in a given population should use NRT to quit. Rather, we posit that a nicotine-dependent individual in a low resource country should have the opportunity to affordably access the medicines to treat his or her tobacco dependence.

\section{Clinical Cessation with NRT: The Evidence}

Tobacco dependence treatment "includes (singly or in combination) behavioral and pharmacological interventions such as brief advice and counseling, intensive support, and administration of pharmaceuticals, that contribute to reducing or overcoming tobacco dependence in individuals and in the population as a whole [3]." In this commentary, we focus specifically on access to NRT, one aspect of tobacco dependence treatment. NRT represent a specific class of nicotine-delivering pharmaceuticals that help people stop smoking by curbing nicotine withdrawal symptoms.

The most recent Cochrane review from 2008, using pooled data from over 40,000 people in 111 trials between 1979-2007, shows that the relative risk of 


$$
\begin{aligned}
& \text { Essential medicines are those that satisfy the priority health care needs of the population. They are } \\
& \text { selected with due regard to the public health relevance, evidence on efficacy and safety and } \\
& \text { comparative cost-effectiveness. Essential medicines are intended to be available within the context of } \\
& \text { functioning health systems at all times in adequate amounts, in the appropriate dosage forms, with } \\
& \text { assured quality and adequate information, and at a price the individual and the community can afford. } \\
& \text { Lists of essential medicines guide the procurement and supply of medicines in the public sector, } \\
& \text { schemes that reimburse medicine costs, medicine donations and local medicine production. Health } \\
& \text { insurance schemes are increasingly using national lists of medicines to prioritize drug subsidization. }
\end{aligned}
$$

Figure 1 The concept of essential medicines

sustained tobacco abstinence with NRT at 6 months or more was 1.58 compared with controls (95\% Confidence Interval (CI): 1.50-1.66) [4]. According to the 2008 US Public Health Service (USPHS) guidelines, the number of smokers needed to be treated with NRT to achieve one quit ranged from 8 for long term use of ( $>14$ weeks) nicotine gum to 10 for nicotine patch and 20 for short term use of nicotine gum [3]. The estimated absolute 6-month smoking abstinence rates for NRT patch and long term gum were $23.4 \%$ and $26.1 \%$, respectively, compared to $13.8 \%$ for placebo [3]. Given the efficacy and relatively low cost of NRT, the addition of NRT to the EML represents an important potential milestone for furthering the goals of global tobacco control while moving towards equitable access to essential medicines.

NRT and brief counseling (in the clinical setting or through telephone quitlines) represent effective and inexpensive clinical treatment approaches for helping the large number of individuals dependent on nicotine worldwide to quit using tobacco. Group and individual counseling increases significantly the odds of successful quitting by a factor of 1.3-1.7 above baseline [3]. The combination of counseling with medications works to synergistically increase quit rates by a factor of 1.7 over counseling alone [3]. We argue that in concert with effective societal approaches to reduce tobacco use through higher tobacco taxes and social denormalization of tobacco use ("unassisted cessation"), clinical treatment options such as counseling and NRT should be available to help those that cannot quit without support. To only promote unassisted cessation without making available NRT to those who cannot or will not quit on their own denies the known addictive nature of nicotine, as well as the known harm of exposing nicotine addicts to stigmatizing policies and economic burdens without the option to help them quit.

By present international standards, NRT can be considered a cost-effective clinical intervention-one estimate predicted that achievement of $25 \%$ global coverage with NRT would cost US\$ 276-279 per disability-adjusted life year averted in East Asia [5]. In a low-income country, the cost of cessation therapy with short-term use of NRT (e.g. 8 weeks of patches) is US $\$ 50$ [5]. Prices of NRT, while still relatively high in the developing world, may be falling. In India, the price of NRT as of 2003 was approximated at $\$ 0.65$ per day for a three month course in 2003 - still high, but $12 \%$ of that in the United States [5]. In the widely respected Disease Control Priorities Project published in 2006, Prabhat Jha and colleagues estimated that providing NRT with an effectiveness of even $1 \%$ above baseline in low and middle countries could save nearly 3 million lives over the next half century; if the effectiveness is $5 \%$, they estimated that over 14 million lives would be saved [6]. These estimates translate into a reasonable range of cost effectiveness in low and middle income countries; comparable to other proven public health strategies (See Figure 2).

Perhaps the most convincing evidence comes from the real-word distribution campaigns of NRT. In 2003, the New York City Department of Health and Mental Hygiene, leaders in instituting public smoking bans, began a widely publicized campaign to distribute free NRT [7]. In total, they estimated that they sent nicotine patches to roughly $5 \%$ of the total adult smoking population in New York City during the short campaign [7]. All of the smokers smoked at least 10 cigarettes daily and $60 \%$ of the smokers were non-white, foreign born or from low-income neighborhoods. When checked 6 months later, more NRT recipients than the control group members successfully quit smoking (33\% vs $6 \%$, $\mathrm{p}=0.0001$ ); with over 6000 successful quits, this program yielded a cost of $\$ 464$ per quit [7].

Recent data specific to LMICs suggest that the medicines would be as efficacious as they are in developed countries, provided the delivery infrastructure is present. These include a study of 341 patients in Brazil that showed greater than 25\% 12-month cessation rate for those receiving counseling and NRT vs. $14.5 \%$ for counseling alone [8], along with other studies in Hong Kong [9] and Venezuela [10] showing similar efficacy. However, the effectiveness of NRT in the real-world in LMICs remains untested. 


\begin{tabular}{|c|c|c|}
\hline $\begin{array}{l}\text { Priority: } \\
\text { Stroke and ischemic } \\
\text { And hypertensive heart } \\
\text { Disease }\end{array}$ & $\begin{array}{l}\text { Intervention: } \\
\text { Combination treatment } \\
\text { with aspirin, beta blocker, } \\
\text { thiazide diuretic, ACE inhibitor, } \\
\text { and statin based on 10-year risk } \\
\text { of cardiovascular disease }\end{array}$ & $\begin{array}{l}\text { Cost /DALY averted: } \\
\$ 2,128\end{array}$ \\
\hline HIV/AIDS & Antiretroviral therapy & $\$ 922 *$ \\
\hline Tobacco addiction & $\begin{array}{l}\text { Nicotine replacement therapy } \\
\text { (NRT) }\end{array}$ & $\$ 396$ \\
\hline Tobacco addiction & $\begin{array}{l}\text { Non price interventions } \\
\text { including tobacco advertising } \\
\text { bans on television, radio and } \\
\text { billboards }\end{array}$ & $\$ 353$ \\
\hline Tuberculosis & $\begin{array}{l}\text { Directly observed short-course } \\
\text { chemotherapy }\end{array}$ & $\$ 301$ \\
\hline $\begin{array}{l}\text { Diarrheal Disease/ } \\
\text { Zinc deficiency }\end{array}$ & Oral rehydration salts & $\$ 73$ \\
\hline $\begin{array}{l}\text { Tobacco addiction } \\
\text { * (sub-Saharan Africa) }\end{array}$ & $\begin{array}{l}\text { Taxation causing } 33 \% \text { price } \\
\text { Increase }\end{array}$ & $\$ 22$ \\
\hline
\end{tabular}

Figure 2 Cost-effectiveness (Cost (USD) per DALY averted) of selected health priorities in LMICs, 2006 (adapted from [28].

\section{The Framework Convention on Tobacco Control and Tobacco Treatment}

In light of the tremendous toll of tobacco use, the world's first global public health treaty, the Framework Convention on Tobacco Control (FCTC), was developed and first signed in 2003 by WHO member states http:// www.who.int/fctc/en/. The FCTC emphasizes both a reduction in the demand and supply of tobacco through the implementation of the MPOWER package of policies [1]. These policies include Monitoring tobacco use, Protecting people from secondhand smoke, Offering treatment for tobacco dependence, Warning people of the dangers of tobacco use, Enforcing advertising bans, and Raising tobacco taxes [1].

To date, however, the majority of global efforts have focused on all the items of the MPOWER package except offering treatment. Some have even remarked, only in half-jest, that the "O" stands for "orphan," not offer treatment. However, Article 14 of the FCTC clearly requires the 169 signatory nations:

"to develop and disseminate appropriate, comprehensive and integrated guidelines based on scientific evidence and best practices, taking into account national circumstances and priorities...and take effective measures to promote cessation of tobacco use and adequate treatment for tobacco dependence... [and] to collaborate with other parties to facilitate accessibility and affordability for treatment of tobacco dependence including pharmaceutical products..."[11].

Progress on implementing the FCTC protocols remains mixed. In 2008, comprehensive treatment services to help users overcome tobacco dependence were available in only 17 countries representing $8 \%$ of the world's population; none of these countries were in the developing world [12]. At the 14th World Conference on Tobacco or Health in Mumbai, India in March 2009, the convened body recommended that by 2012 , the majority of parties to the FCTC should begin to provide national tobacco cessation efforts as recommended under Article 14.

While the FCTC is catalyzing some tobacco control success worldwide, the tobacco industry continues to market aggressively and successfully. Smoking prevalence remains close to $25 \%$ in the 30 high- and middleincome countries belonging to the Organisation for 
Economic Cooperation and Development (OECD) and is increasing in LMIC, especially among women. Currently, in Matlab, Bangladesh, nearly $70 \%$ of men and $33 \%$ of women smoke or use smokeless tobacco [13]. The effect of these practices is striking with $79 \%$ of deaths in Matlab attributed at present to non-communicable diseases, many of which are linked to the use of tobacco [14]. Male Bangladeshi smokers currently spend twice as much on tobacco as on education, health, and other household expenditures combined [15]. To this end, the inclusion of NRT on the EML may help catalyze the inclusion of tobacco treatment into clinical systems across the developing world.

\section{Challenges \& Counter-arguments Alternative Cessation Methods}

Are we in danger of over-hyping NRT for use in developing countries or "over-medicalizing" the treatment of tobacco use? We acknowledge that these medicines are not a panacea, and that most evidence for their efficacy comes from the developed world. NRT and behavioral programs typically help fewer than $30 \%$ of smokers who use them to quit over the long-term. Cultural norms around tobacco use and cessation, as well as knowledge about the harms of tobacco, are different in LMIC compared to developed countries. Investment in upstream approaches to modify the social climate around tobacco use, bans on advertising and promotion, and clean indoor air laws are important first approaches in resource-scarce public health environments[16]. While there is some controversy around the population-wide or "real-world" effect of NRT in developed countries $[17,18]$, new evidence from Massachusetts suggests a likely association between increased insurance coverage for, and use of, smoking cessation medications with increased quit attempts and decreased smoking prevalence among low-income smokers on public insurance [19]. Furthermore, Grassi et al (2009) showed that concomitant clean indoor air laws can synergistically increase rates of successful cessation among smokers treated for tobacco use in a clinical setting[20].

What is clear, regardless of one's point of view on the best method of cessation, is that nicotine-dependent patients deserve the right to affordable access for these treatments if they so choose. This is especially true considering the cost-effectiveness of NRT compared to many other widely used clinical interventions (See Figure 2). For example, combination use of statins and anti-hypertensives, all WHO essential medicines [2,21] used for the control of cardiovascular disease is much less cost-effective than NRT. Further, the use of directly observed chemotherapy for tuberculosis or tobacco advertising bans feature comparable cost-effectiveness to NRT use - estimates that hold up in both developed and developing world settings.
To this end, the newly acquired WHO essential medicine status can and should encourage WHO member states in low and middle income regions to register NRT for use in their countries. While more evidence is needed to understand quit rates using NRT in LMICs as well as optimal ways to provide treatment services within resource-poor settings, there is no prima facie reason to believe that NRT is not effective in the developing world (reviewed below). In fact, the EML committee did not demand confirmatory proof of effectiveness in the developing world before including other medications such as proton pump inhibitors and oncologic chemotherapeutics in the EML.

Just how NRT use is best parceled out within the larger tobacco treatment clinical context in low resource settings remains an open question deserving of further rigorous empirical study. To be sure, the preventive and treatment approaches need not be viewed as mutually exclusive, even in resource-starved environments. The approaches can complement one another [20] and smoking cessation services are most effective in the context of coordinated tobacco control [12].

\section{Role of the Pharmaceutical Industry}

In a field sensitive to conflict of interest and accustomed to dealing with now infamous tactics of tobacco industry deceit [22] there is some understandable skepticism of the role of pharmacotherapy in cessation [23], particularly regarding the reliability of industry-backed trials or excessive hype over these medicines. This skepticism, however, does not change the fact that the drugs have been shown to work empirically and, based on this evidence, have been incorporated into major national and international health platforms (including the FCTC and EML). The large scale distribution of free NRT by large urban public health agencies underscores this trend [7].

If anything, the essential medicine status of NRT should now help break down structural and price barriers maintained by the pharmaceutical industry that prohibit patients, particularly in lower income countries, from accessing these medicines in an affordable manner (such as being sold in single use quantities). Targeted expansion of generic production of these medicines, including the use of humanitarian licensing and enhanced drug donation schemes to augment NRT availability and drive costs down, are needed urgently for these cessation programs to work in concert with other public tobacco control strategies.

\section{Uptake and Delivery of NRT in LMIC}

It is unclear whether the packaging and delivery of a pharmacotherapy is tenable currently for many smokers in LMIC. There is little to no cultural awareness of how these medicinal products could help in cessation, particularly in an environment where cessation is not normative. In fact, the use of NRT has been largely untested in LMIC 
outside of a few studies [5,24]. Task-shifting treatment services, as levered by the HIV/AIDS and Tuberculosis (TB) treatment communities, as well as deregulation of the medicines for over-the-counter treatment can help, but require further detailed study in LMIC for NRT. Cessation efforts should be naturally integrated into ongoing efforts to strengthen primary care. Critically, the process of working with existing treatment providers in LMIC to identity target populations (such as patients with TB) to offer effective counseling and deliver NRT to a larger group of tobacco users worldwide is a necessary step to reduce tobacco use $[5,24]$.

\section{Financing}

A final thorny issue, currently unanswered, is who will actually pay for the treatments? Is it the role of the individual patient or of the government or even of large pharmaceutical companies distributing these medications for free or at reduced prices? Lists of essential medicines guide the procurement and supply of medicines in the public sector, with several LMIC with social health insurance programs subsidizing coverage of EML-listed medicines. The use of government tax on tobacco revenues could help finance telephone quit lines and clinical cessation services, including distribution of NRT to nicotine dependent patients [9].

It is clear that governments need to prioritize their funding of drugs on the EML proportional to the expected public health gains. Further, WHO and governments must negotiate with NRT manufacturers to ensure that NRTs are affordable in key LMIC markets. Given the growing burden of tobacco, even low-income countries (e.g. Bangladesh) may find ways to prioritize multimodal tobacco control strategies. These strategies, including cessation treatment, can naturally synchronize with a growing political, social and technical movement to drive resources to control non-communicable chronic diseases (NCDs) and their risk factors (particularly tobacco) through a planned United Nations high-level meeting on NCDs in September 2011 [25-27].

As outlined in the most recent WHO MPOWER report on global tobacco, "in the vast majority of lowand middle-income countries, the cost of cessation assistanceis not covered by the government, and $8 \%$ of middle income and $29 \%$ of low-incomecountries provide no assistance at all." [9] Hence, it is imperative for countries to make the medicines available and more affordable (through drug registration and direct import) to individual nicotine-dependent patients who want them at pharmacies in both urban and rural locales.

Further, it is reasonable for countries to consider stocking NRT for use in ambulatory clinical settings among particularly high-risk tobacco users such as newly diagnosed TB patients or patients with severe chronic obstructive pulmonary disease. Whether a population-based effort to promote more widespread NRT use would be clinically appropriate or economically feasible in the near future remains an open question in need of more study.

\section{Concluding thoughts}

Though a vital part of tobacco control, clinical tobacco treatment is often neglected. It is now clear that neither public health interventions like smoking bans or increased taxes, nor clinical strategies like offering NRT, are sufficient alone. Lasting progress toward reducing the burden of tobacco will only be made by integrating these crucial legislative, financial, and clinical approaches. Coupled with the FCTC and heightened political attention on NCDs and tobacco control, NRT provides another valuable tool for reducing the global burden of tobacco use. It is now more important than ever that countries swiftly register these medicines, and liaise with appropriate generic manufacturers to augment availability and harmonize clinical cessation into systems-level clinical care. The real question now is when will we act?

\section{Author details}

${ }^{1}$ Weill Cornell/Rockefeller/Sloan-Kettering Tri-Institutional MD-PhD Program, New York, New York, USA. '2Division of General Medicine at Brigham and Women's Hospital and the Department of Health Care Policy at Harvard Medical School, Boston, Massachusetts, USA. ${ }^{3}$ Executive Director of the International Centre for Diarrhoeal Disease Research, (ICDDR, B), Dhaka, Bangladesh. ${ }^{4}$ Senior Vice President for Global Health Policy at PepsiCo, Inc, Purchase, New York, USA and is the former Executive Director for the World Health Organization, Geneva, Switzerland. ${ }^{5} 420$ E $70^{\text {th }}$ St, Ste $10 \mathrm{M}$, New York, NY 10021.

\section{Authors' contributions}

All authors contributed to the writing and reviewing of this work.

\section{Competing interests}

DY is a member of the Board of Directors of Vitality USA, a Discovery SA institution that supports tobacco cessation and other preventive measures and is not funded by the pharmaceutical industry or manufacturers of NRT. As a WHO staff member, DY actively pushed for tobacco cessation as part of the WHO Framework Convention of Tobacco Control. SPK is a member of the Board of Directors of Universities Allied for Essential Medicines, a nongovernmental organization supporting access to essential drugs and vaccines in resource-poor countries.

Received: 7 May 2010 Accepted: 19 November 2010

Published: 19 November 2010

\section{References}

1. World Health Organization (WHO): WHO report on the Global Tobacco Epidemic, 2008: The MPOWER package. WHO, Geneva; 2008.

2. World Health Organization (WHO): 16th WHO Model List of Essential Medicines.[http://www.who.int/selection_medicines/list/en/], Accessed: November 23, 2009.

3. Fiore MC, et al: Treating Tobacco Use and Dependence: 2008 Update. Rockville, MD: US Department of Health and Human Services. Public Health Service; 2008.

4. Stead LF, Perera R, Bullen C, Mant D, Lancaster T: Nicotine replacement therapy for smoking cessation. Cochrane Database of Systematic Reviews $2008,1$.

5. Gilbert AR, Pinget C, Bovet P, Cornuz J, Shamlaye C, Paccaud F: The cost effectiveness of pharmacological smoking cessation therapies in 
developing countries: a case study in the Seychelles. Tob Control 2004, 13:190-195.

6. Jha Prabhat, Chaloupka JFrank, Moore James, Gajalakshmi Vendhan, Gupta CPrakash, Peck Richard, Asma Samira, Zatonski Witold: "Tobacco Addiction.". Disease Control Priorities in Developing Countries. 2 edition. New York: Oxford University Press; 2006, 869-886.

7. Miller N, Frieden TR, Liu SY, Matte TD, Mostashari F, Deitcher DR, Cummings KM, Chang C, Bauer U, Bassett MT: Effectiveness of a largescale distribution programme of free nicotine patches: a prospective evaluation. Lancet 2005, 365:1849-1854.

8. Chatkin JM, Mariante de Abreu C, Haggstram FM, Wagner MB, Fritscher CC: Abstinence rates and predictors of outcome for smoking cessation: do Brazilian smokers need special strategies? Addiction 2004, 99:778-784.

9. Abdullah AS, Hedley AJ, Chan SS, Ho WW, Lam TH: Establishment and evaluation of a smoking cessation clinic in Hong Kong: a model for the future service provider. J Public Health (Oxf) 2004, 26:239-244.

10. Herrera N, Franco R, Herrera L, Partidas A, Rolando R, Fagerstrom KO: Nicotine gum, 2 and $4 \mathrm{mg}$, for nicotine dependence. A double-blind placebo-controlled trial within a behavior modification support program. Chest 1995, 108:447-451.

11. WHO Framework Convention on Tobacco Control. 2003 [http://www. who.int/fctc/en/], Accessed 30 April 2009.

12. World Health Organization (WHO): WHO report on the Global Tobacco Epidemic, 2009: Implementing smoke-free environments. WHO Geneva; 2009.

13. Razzaque ANL, Mustafa AHMG, Karar AZ, Islam MS, Yunus M: Sociodemographic differential of selected non-communicable disease risk factors amont adults in Matlab: findings from a WHO STEPS survey. AsiaPacific Public Health Journal .

14. Health and Demographic Surveillance System-Matlab. Registration of Health and Demographic Events 2007. ICDDR, B Scientific Report 106 2009, 41.

15. Efroymson D, Ahmed S, Townsend J, Alam SM, Dey AR, Saha R, Dhar B, Sujon Al, Ahmed KU, Rahman O: Hungry for tobacco: an analysis of the economic impact of tobacco consumption on the poor in Bangladesh. Tob Control 2001, 10:212-217.

16. Wakefield MA, Durkin S, Spittal MJ, Siahpush M, Scollo M, Simpson JA, Chapman S, White V, Hill D: Impact of tobacco control policies and mass media campaigns on monthly adult smoking prevalence. Am J Public Health 2008, 98:1443-1450.

17. Walsh RA: Over-the-counter nicotine replacement therapy: a methodological review of the evidence supporting its effectiveness. Drug Alcohol Rev 2008, 27:529-547.

18. Chapman S, MacKenzie R: The global research neglect of unassisted smoking cessation: causes and consequences. PLoS Med 7:e1000216.

19. Land T, Warner D, Paskowsky M, Cammaerts A, Wetherell L, Kaufmann R, Zhang L, Malarcher A, Pechacek T, Keithly L: Medicaid Coverage for Tobacco Dependence Treatments in Massachusetts and Associated Decreases in Smoking Prevalence. PLoS One 2010, 5:e9770.

20. Grassi MC, Enea D, Ferketich AK, Lu B, Nencini P: A smoking ban in public places increases the efficacy of bupropion and counseling on cessation outcomes at 1 year. Nicotine Tob Res 2009, 11:1114-1121.

21. Kishore SP, Herbstman BJ: Adding a medicine to the WHO model list of essential medicines. Clin Pharmacol Ther 2009, 85:237-239.

22. Bitton A, Neuman MD, Barnoya J, Glantz SA: The p53 tumour suppressor gene and the tobacco industry: research, debate, and conflict of interest. Lancet 2005, 365:531-540.

23. Etter JF, Burri M, Stapleton J: The impact of pharmaceutical company funding on results of randomized trials of nicotine replacement therapy for smoking cessation: a meta-analysis. Addiction 2007, 102:815-822.

24. Pinget C, Martin E, Wasserfallen JB, Humair JP, Cornuz J: Cost-effectiveness analysis of a European primary-care physician training in smoking cessation counseling. Eur J Cardiovasc Prev Rehabil 2007, 14:451-455.

25. International Diabetes Federation: Commonwealth Heads of Government Meeting. Joint Statement by the International Diabetes Federation, International Union Against Cancer and World Heart Federation 2009 [http:// www.idf.org/webdata/docs/CHOGM-Joint-Statement.pdf], Accessed: March 22, 2010.

26. Stuckler D, Basu S, Mckee M: Drivers of inequality in millennium development goal progress: a statistical analysis. PLOS Med 7:e1000241.

27. Morris K: UN raises priority of non-communicable diseases. Lancet 375:1859.
28. Jha Prabhat, Chaloupka JFrank, Moore James, Gajalakshmi Vendhan, Prakash CGupta, Peck Richard, Asma Samira, Zatonski Witold: Disease Control Priorities in Developing Countries. 2 edition. New York: Oxford University Press; 2006, 35-86.

doi:10.1186/1744-8603-6-22

Cite this article as: Kishore et al:: Enabling access to new WHO essential medicines: the case for nicotine replacement therapies. Globalization and Health 2010 6:22.

\section{Submit your next manuscript to BioMed Central and take full advantage of:}

- Convenient online submission

- Thorough peer review

- No space constraints or color figure charges

- Immediate publication on acceptance

- Inclusion in PubMed, CAS, Scopus and Google Scholar

- Research which is freely available for redistribution

Submit your manuscript at www.biomedcentral.com/submit
C Biomed Central 